\title{
Digestibilidade, consumo, desempenho e características de carcaça de tourinhos mestiços confinados com cana-de-açúcar ou silagem de sorgo
}

\section{Andréa Pereira Pinto ${ }^{1}$, Willian Gonçalves do Nascimento ${ }^{2}$, José Jorge dos Santos Abrahão², Daniel Perotto ${ }^{3}$, José Luiz Moletta ${ }^{4}$, Simony Marta Bernardo Lugão ${ }^{2}$}

\author{
1 Universidade Federal do Ceará - UFC, Departamento de Zootecnia, CEP: 60355-901, Fortaleza, CE. \\ 2 IAPAR, Caixa postal 564, CEP: 87701-970, Paranavaí, PR. \\ 3 IAPAR - Pólo Regional de Curitiba. \\ 4 IAPAR - Fazenda Modelo - Ponta Grossa.
}

RESUMO - Objetivou-se avaliar a digestibilidade, o consumo, o desempenho e as características de carcaça em tourinhos mestiços confinados alimentados com dietas balanceadas, à base de cana-de-açúcar ou de silagem de sorgo. Na avaliação da digestibilidade e no confinamento, foram utilizados, respectivamente, quatro e 18 tourinhos mestiços por dieta, alojados em baias individuais, em delineamento inteiramente casualizado, com dois tratamentos (silagem de sorgo $+1,0 \%$ do peso vivo em concentrado; e cana-de-açúcar picada $+1,2 \%$ do peso vivo em concentrado). As dietas foram calculadas para que tivessem em torno de $12 \%$ de proteína bruta. Não foi observada diferença no consumo e na digestibilidade de matéria seca, matéria orgânica, proteína bruta, fibra em detergente neutro e carboidratos totais entre os animais alimentados com silagem de sorgo ou canade-açúcar. Os animais alimentados com cana-de-açúcar apresentaram pior conversão alimentar e menor ganho médio diário. Não foram observadas diferenças no peso vivo, peso de carcaça quente, rendimento de carcaça, conformação das carcaças, área de olho-de-lombo, espessura da gordura subcutânea, espessura de coxão, cor, textura e marmoreio da carne e porcentagem de osso, de músculo e de gordura. As carcaças foram classificadas, na média, como muito boas menos. A cana-de-açúcar em substituição à silagem de sorgo não influenciou as variáveis estudadas, com exceção da conversão alimentar, do ganho médio diário, da ingestão e da digestibilidade de fibra em detergente ácido. A cana-de-açúcar, se utilizada como único volumoso, pode reduzir o desempenho dos animais.

Palavras-chave: conversão alimentar, espessura de gordura subcutânea, ganho médio diário, nutrientes digestíveis totais, rendimento de carcaça

\section{Digestibility, intake, performance and carcass characteristics of young crossbred bulls in feedlot with sugar cane or sorghum silage}

\footnotetext{
ABSTRACT - The objective of the present study was to evaluate the digestibility, intake, performance and carcass characteristics in young crossbred bulls fed balanced diets based on sugarcane or sorghum silage. In the digestibility assessment in the feedlot, four and eighteen young crossbred young bulls were used per diet, kept in individual stalls, in a randomized complete experimental design with two diets (sorghum silage $+1.0 \%$ live weight in concentrate and chopped sugar cane $+1.2 \%$ of live weight concentrate). The diets were formulated to have around $12 \%$ crude protein. No difference was observed between the diets for intake and digestibility of dry matter, organic matter, crude protein, neutral detergent fiber and total carbohydrates among the animals fed sorghum silage or sugarcane. The animals fed with sugar cane yielded worse feed conversion and lower daily gain. No differences were observed for live weight, hot carcass weight, carcass dressing, carcass conformation, loin eye area, subcutaneous fat thickness, cushion thickness, meat color, texture and marbling and percentage of bone, muscle and fat The mean classification of the carcasses was very good minus. Substituting sugar cane for sorghum silage did not influence the studied variables, except feed conversion, daily gain and acid detergent fiber intake and digestibility. Sugar cane can reduce animal performance if used as the only source of forage.
}

Key Words: carcass yield, daily weight gain, feed conversion, subcutaneous fat thickness, total digestible nutrients 


\section{Introdução}

A digestibilidade, juntamente com o consumo, determina grande parte do valor nutritivo do alimento, pois a fração digerida é que será absorvida e metabolizada pelo animal. A quantidade total de nutrientes absorvidos durante a alimentação depende também da digestibilidade, apesar de o consumo ser responsável pela maior parte das diferenças entre os alimentos (Silva, 2006). Além da limitação física imposta pelo teor de fibra em detergente neutro na dieta e sua digestibilidade, o consumo também pode ser regulado pelo controle fisiológico, em que o animal ingere alimento até satisfazer sua demanda energética.

A alimentação é um dos fatores que determinam a qualidade da carne bovina, afetando, direta e indiretamente, a qualidade do produto final. Os efeitos diretos estão relacionados à composição química e às características quantitativas da carcaça e interferem principalmente na proporção do tecido adiposo em relação ao muscular. Os efeitos indiretos são os relacionados à redução da idade de abate, que pode influenciar a composição dos tecidos (menor porcentagem de colágeno) e contribuir para a melhoria do produto final (Abrahão et al., 2005).

Para que o confinamento de bovinos seja economicamente viável, a utilização de alimentos alternativos de menor custo torna-se imprescindível. Assim, alimentos como a cana-de-açúcar e a silagem de sorgo podem ser utilizados para substituir a silagem de milho nos confinamentos. Entretanto, como a qualidade da cana-deaçúcar é inferior à da silagem, suas limitações nutricionais devem ser consideradas e corrigidas, permitindo que os animais apresentem desempenho similar ao obtido com outros volumosos, e com menor custo (Aroeira et al., 1995).

Assim, este trabalho foi realizado com o objetivo de avaliar a digestibilidade, o consumo, o desempenho e as características de carcaças em tourinhos mestiços confinados, alimentados com dietas balanceadas à base de cana-de-açúcar ou de silagem de sorgo.

\section{Material e Métodos}

O experimento foi realizado no setor de confinamento do Instituto Agronômico do Paraná, na Estação Experimental de Paranavaí. Para avaliação da digestibilidade, foram utilizados quatro animais por tratamento (silagem de sorgo + 1,0 \% PV de concentrado e cana de açúcar picada + 1,2\% PV de concentrado), em delineamento inteiramente casualizado. Os animais, provenientes do experimento de desempenho e já adaptados às dietas, foram alojados individualmente em baias de $28 \mathrm{~m}^{2}$ com piso de concreto, bebedouro e cocho de alvenaria coberto, com $60 \mathrm{~cm}$ de profundidade e $3 \mathrm{~m}$ de comprimento, e alimentados duas vezes ao dia (às 9 e às 15 h). Houve uma fase de adaptação às baias, de 15 dias, e uma fase de coleta de fezes, de 4 dias.

Para o fornecimento de volumoso no período de coleta, calculou-se a média do consumo dos três últimos dias de adaptação. Os animais foram pesados, após jejum de 12 horas, no início e fim do período experimental, considerando o peso médio para cálculo do tamanho metabólico (kg PV ${ }^{0,75}$ ). O consumo de alimentos foi registrado diariamente pela pesagem da quantidade fornecida e das sobras do dia anterior. A coleta total de fezes foi feita diretamente do piso da baia (concretado) imediatamente após o animal defecar, registrando-se a produção diária por animal. Diariamente, coletaram-se amostras de alimentos e de fezes, proporcionais à produção total. As amostras foram acondicionadas em sacos plásticos devidamente etiquetados, guardadas em congelador a $-18^{\circ} \mathrm{C}$ e, ao final do período de coleta, foram agrupadas em uma amostra composta de fezes de cada animal.

Os alimentos e as fezes foram submetidos a determinações de matéria seca (MS), proteína bruta (PB), extrato etéreo (EE), matéria mineral (MM), fibra em detergente neutro (FDN) e fibra em detergente ácido (FDA), conforme metodologias descritas por Silva \& Queiroz (2002). Os carboidratos totais, os nutrientes digestíveis totais (NDT) e a energia metabolizável foram calculados segundo Sniffen et al. (1992), em que NDT = (\% proteína bruta digestível + \% carboidratos totais digestíveis) + 2,25 (\% extrato etéreo digestível). No cálculo da energia metabolizável, considerou-se que $1 \mathrm{~kg}$ de NDT equivale a 4,409 Mcal de energia digestível e, para a transformação em energia metabolizável, utilizou-se o valor de $82 \%$ de eficiência de utilização da energia digestível, conforme NRC (1996). O coeficiente de digestibilidade aparente da matéria seca e dos demais nutrientes foi calculado segundo Silva \& Leão (1979).

Para avaliação do desempenho e das características de carcaça, foram utilizados 36 tourinhos mestiços, com idade média de 20 a 22 meses, peso médio inicial de $329 \pm 44$ kg, oriundos do programa de cruzamento da Estação. O delineamento experimental utilizado foi o inteiramente casualizado, com dois tratamentos, cada um com 18 animais (repetições).

Os animais foram alojados em baias individuais, com acesso a cocho de alimentação e água, e alimentados duas vezes ao dia (às 9 e às 15 h). O volumoso foi fornecido à vontade e o concentrado, calculado com base no peso 
vivo (PV) em matéria seca, reajustado a cada 28 dias, após a pesagem dos animais. As dietas (tratamentos) foram: silagem de sorgo $+1,0 \%$ PV de concentrado e cana-deaçúcar picada $+1,2 \%$ PV de concentrado. O concentrado foi à base de farelo de soja, milho, ureia, calcário e sal branco adicionado de microelementos, e as dietas foram calculadas para que tivessem em torno de $12 \%$ de proteína bruta (Tabela 1).

A duração do confinamento, de 26 de junho a 6 de novembro de 2007, totalizou 133 dias, após período de 15 dias de adaptação. Os animais foram pesados, após jejum de 12 horas, no início e fim do período experimental, com pesagens intermediárias a cada 28 dias.

$\mathrm{O}$ abate foi realizado segundo a rotina do frigorífico comercial. O rendimento de carcaça foi obtido a partir do peso vivo do animal em jejum, antes do envio ao frigorífico, e do peso da carcaça quente, determinado ao abate.

As meias-carcaças foram lavadas, identificadas e acondicionadas em câmara fria mantida à temperatura de $1{ }^{\circ} \mathrm{C}$, na qual permaneceram por um período de 24 horas. Posteriormente, foram retiradas para que se procedessem as avaliações qualitativas e quantitativas das carcaças.

A conformação da carcaça foi avaliada subjetivamente, segundo escala de pontos sugerida por Müller (1980). O comprimento de carcaça foi determinado com trena milimetrada, comparando-se a distância desde a borda anterior do osso púbis ao bordo cranial medial da primeira costela. Com auxílio de um compasso de madeira com pontas metálicas, determinaram-se o comprimento de perna e espessura do coxão, respectivamente, pela distância entre o bordo anterior do osso púbis e um ponto médio dos ossos da articulação do tarso e a distância entre a face lateral e medial da porção superior do coxão, medidas com trena milimetrada. A área do músculo Longissimus dorsi ou área de olho de lombo foi determinada na metade direita da carcaça, na qual se efetuou um corte transversal entre a $12^{\mathrm{a}}$ e $13^{\mathrm{a}}$ costelas, expondo-se a superfície do músculo, sobre a qual foi determinada com um planímetro a massa muscular, em $\mathrm{cm}^{2}$.

A determinação da espessura da gordura de cobertura subcutânea (EGS) foi efetuada na região do corte, entre a $12^{\mathrm{a}}$ e $13^{\underline{a}}$ costelas, acima do músculo L. dorsi, com auxílio de um paquímetro, calculando-se a média de duas determinações por carcaça. Na face exposta do músculo $L$. dorsi, foram determinadas, visualmente, a cor do músculo após exposição ao ar por 30 minutos, a textura do músculo, determinada pelo tamanho dos fascículos (granulação de carne), e o marmoreio, que expressa a gordura intramuscular, conforme escala de pontos proposta por Müller (1980).

As porcentagens de osso, músculo e gordura na carcaça foram determinadas utilizando-se a seç̧ão do

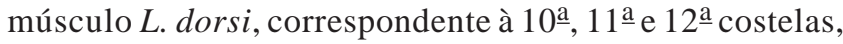
cujo corte foi obtido segundo metodologia descrita por Hankins \& Howe (1946). A partir do segmento obtido, realizou-se a separação física de osso, músculo e gordura, e cada componente foi pesado separadamente.

As porcentagens obtidas nessa secção foram colocadas nas equações de regressão obtidas por Müller et al. (1973) transformando esses dados aos correspondentes à 9aㅡ, 10aㅡ e 11므 costelas: $\% \mathrm{M}=6,292+0,910 \mathrm{X}_{1} ; \% \mathrm{O}=2,117$ $+0,860 \mathrm{X}_{2}$ e $\% \mathrm{G}=1,526+0,913 \mathrm{X}_{3}$, em que $\mathrm{X}_{\mathrm{i}}$ representa, respectivamente, os percentuais de músculo, osso e gordura correspondentes.

Os percentuais correspondentes à $9 \underline{a}, 10^{\underline{a}}$ e $11^{\mathrm{a}}$ costelas, foram inseridos nas equações de regressão, segundo Hankins \& Howe (1946), obtendo-se assim, os percentuais

Tabela 1 - Composição em ingredientes e nutricional das dietas, com base na matéria seca

\begin{tabular}{|c|c|c|}
\hline Ingrediente & Silagem de sorgo $+1,0 \%$ concentrado & Cana-de-açúcar $+1,2 \%$ concentrado \\
\hline Silagem de sorgo (\%) & 54,50 & \\
\hline Cana-de-açúcar (\%) & & 36,84 \\
\hline Farelo de soja (\%) & 8,83 & 12,26 \\
\hline Ureia (\%) & 0,50 & 0,70 \\
\hline Calcário calcítico (\%) & 0,50 & 0,70 \\
\hline Sal branco* $(\%)$ & 0,25 & 0,35 \\
\hline Matéria seca (\%) & 44,6 & 51,9 \\
\hline Matéria orgânica (\% na MS) & 94,6 & 96,8 \\
\hline Matéria mineral (\% na MS) & 4,4 & 3,2 \\
\hline Proteína bruta (\% na MS) & 13,7 & 12,7 \\
\hline Fibra em detergente ácido (\% na MS) & 41,5 & 32,9 \\
\hline Fibra em detergente ácido (\% na MS) & 22,5 & 15,8 \\
\hline
\end{tabular}

*Adicionado de microelementos, composição por kg do produto: Zn - 5.000 mg; Cu - 2.000 mg; Co - 30 mg; Se - 67 mg; I - 155 mg; Na - 387 g. 
de músculo (PM), osso (PO) e gordura (PG) nas carcaças estudadas, de modo que $\mathrm{PM}=15,56+0,81 \mathrm{M} ; \mathrm{PO}=4,30+$ $0,61 \mathrm{O}$ e $\mathrm{PG}=3,06+0,82 \mathrm{G}$, em que $\mathrm{M}$, $\mathrm{O}$ e $\mathrm{G}$ são respectivamente, os valores de músculo, osso e gordura encontrados pelas equações de Müller et al. (1973).

Todas as características em estudo foram submetidas ao teste de normalidade. A característica EGS não obedeceu à distribuição normal e foi analisada pelo método dos modelos lineares generalizados, utilizando-se o procedimento GENMOD (SAS, 2004). As demais características apresentaram distribuição normal e foram submetidas à análise de variância pela metodologia dos quadrados mínimos, por meio do procedimento GLM (SAS, 2004) e as médias comparadas pelo teste T a $5 \%$ de probabilidade, utilizando-se o programa SAS (2004).

\section{Resultados e Discussão}

Não foi observada diferença significativa $(\mathrm{P}>0,05)$ na digestibilidade e no consumo de matéria seca, matéria orgânica, proteína bruta, fibra em detergente neutro e carboidratos totais entre os animais alimentados com silagem de sorgo ou cana-de-açúcar picada (Tabela 2). Também não houve influência das dietas nos valores de nutrientes digestíveis totais e energia metabolizável.

O aumento do fornecimento de concentrado (1,2\% do peso vivo) nos animais alimentados com dietas à base de cana-de-açúcar como volumoso exclusivo foi suficiente para aumentar a digestibilidade e o consumo das dietas ao nível semelhante àquele encontrado para as dietas com silagem de sorgo. Somente a digestibilidade e o consumo de fibra em detergente ácido foram menores $(\mathrm{P}<0,05)$ nos animais alimentados com cana-de-açúcar. O efeito positivo do aumento do fornecimento de concentrado em dietas à base de cana-de-açúcar também foi observado por Moraes et al. (2008a), que, avaliando cana-de-açúcar tratada ou não com óxido de cálcio, fornecida com diferentes níveis de concentrado (0,0; 0,5 e 1,0\% do peso corporal) para novilhas de corte em confinamento, relataram que o aumento do fornecimento de concentrado na dieta com cana-de-açúcar melhorou a ingestão e a digestibilidade da maioria dos nutrientes, resultando em melhor desempenho animal. Em outro artigo, Moraes et al. (2008b), com os mesmos níveis de concentrado, observaram efeito linear positivo do nível de concentrado na dieta com cana-de-açúcar na melhora do consumo, nas digestibilidades total e ruminal da maioria dos nutrientes e no balanço de compostos nitrogenados.

O menor consumo e a menor digestibilidade da fibra em detergente ácido nas dietas com cana-de-açúcar provavelmente estão relacionados ao menor teor de fibra na dieta com cana-de-açúcar (Tabela 1) e ao maior teor de lignina, que, conforme dados de literatura, pode variar de 7,9 \% (Mendonça et al., 2004) a $12 \%$ (Pereira et al., 2000). A cana-de-açúcar apresenta elevada fração de componentes solúveis, decorrente da alta concentração de açúcares solúveis, que poderia suportar rápido crescimento microbiano no rúmen. Entretanto, a baixa digestão da fibra potencialmente degradável, com significativo efeito de

Tabela 2 - Médias e coeficientes de variação para nutrientes digestíveis totais, energia metabolizável, coeficientes de digestibilidade aparente dos nutrientes e consumo médio diário dos nutrientes das dietas

\begin{tabular}{|c|c|c|c|}
\hline & Silagem de sorgo $+1,0 \%$ concentrado & Cana-de-açúcar $+1,2 \%$ concentrado & CV (\%) \\
\hline Nutrientes digestíveis totais (\%) & 63,7 & 66,9 & 5,4 \\
\hline Energia metabolizável (Mcal/kg) & 2,3 & 2,4 & 5,4 \\
\hline Matéria seca & 62,0 & 65,7 & 5,8 \\
\hline Matéria orgânica & 63,2 & 66,7 & 5,9 \\
\hline Proteína bruta & 62,0 & 64,8 & 5,7 \\
\hline Carboidratos totais & 63,3 & 66,8 & 6,3 \\
\hline \multicolumn{4}{|l|}{ Consumo médio diário } \\
\hline Matéria seca (g/kg PV ${ }^{0,75} /$ dia) & 96,5 & 102,0 & 5,5 \\
\hline Matéria seca (\% PV) & 2,1 & 2,2 & 8,8 \\
\hline Matéria orgânica (g/kg PV0,75/dia) & 92,3 & 98,8 & 5,5 \\
\hline Nutrientes digestíveis totais (g/kg PV $0,75 /$ dia) & 61,5 & 68,1 & 6,1 \\
\hline
\end{tabular}

CV = coeficiente de variação.

Médias seguidas de letras diferentes na linha diferem entre si $(P<0,05)$, pelo teste $\mathrm{T}$. 
repleção, levaria à limitação da ingestão de matéria seca em animais de maior potencial de produção (Pereira et al., 2000).

Apesar de não haver efeito das dietas sobre a ingestão de matéria seca, houve pior conversão alimentar e menor $(\mathrm{P}<0,05)$ ganho médio diário (Tabela 3$)$ para os animais alimentados com cana-de-açúcar. Entretanto, não foram observadas diferenças significativas $(\mathrm{P}>0,05)$ no peso vivo em jejum anterior ao abate, no peso de carcaça quente e no rendimento de carcaça. O peso vivo inicial médio pode ter influenciado esses resultados, uma vez que os animais alimentados com silagem de sorgo apresentaram, aproximadamente $12 \mathrm{~kg}$ a menos que o peso inicial dos animais alimentados com cana-de-açúcar.

A conformação é uma avaliação subjetiva da expressão muscular da carcaça e incluiu principalmente a cobertura muscular da parte traseira, onde estão localizados os cortes de maior valor comercial. Carcaças com melhor conformação são preferidas por apresentarem músculos com melhor aparência para o consumidor, com tendência a menor proporção de osso e maior porção comestível (Müller, 1980). Não foi observada influência $(\mathrm{P}>0,05)$ da dieta na conformação das carcaças, que, na média, segundo a metodologia, se classificaram como muito boas menos (Tabela 4).

Não foram observadas diferenças significativas entre as dietas para área de olho-de-lombo, espessura da gordura subcutânea, espessura de coxão, cor, textura, marmoreio e porcentagem de osso, músculo e gordura (Tabela 4).
A área de olho-de-lombo expressa a musculosidade da carcaça e está diretamente correlacionada ao peso da carcaça (Costa et al. 2002), assim, os valores encontrados neste trabalho (Tabela 4) estão de acordo com o peso de abate observado. Como não houve diferença no peso de carcaça, não era esperada diferença para os valores de área de olhode-lombo.

A espessura da gordura subcutânea não diferiu $(\mathrm{P}>0,05)$ entre os tratamentos e variou de 4,1 a 4,3 mm, se enquadrando no exigido pelos frigoríficos, que, segundo Costa et al. (2002), seria entre 3 e $6 \mathrm{~mm}$ na cobertura da carcaça. O comprimento de carcaça e o comprimento da perna foram maiores nos animais alimentados com silagem de sorgo, provavelmente em decorrência do maior peso vivo e peso de carcaça quente desses animais.

Os valores atribuídos à cor, com média de 3,6 pontos, equivalem à coloração entre vermelha e vermelha levemente escura e estão um pouco abaixo dos relatados por Abrahão et al. (2005) para tourinhos alimentados com dietas com diferentes níveis de substituição do milho por resíduo úmido da extração da fécula de mandioca. $\mathrm{O}$ aspecto da carne produzida por esses animais pode ser considerado atraente para o consumidor, uma vez que carnes escuras são pouco atrativas e podem estar relacionadas ao manejo pré-abate inadequado (Abrahão et al., 2005). Apesar de machos não-castrados apresentarem carne com coloração mais escura, os resultados obtidos mostram que é possível

Tabela 3 - Desempenho de tourinhos confinados com dietas à base de cana-de-açúcar ou silagem de sorgo

\begin{tabular}{|c|c|c|c|c|c|c|}
\hline Tratamento & $\begin{array}{l}\text { Peso vivo } \\
\text { inicial (kg) }\end{array}$ & $\begin{array}{l}\text { Peso vivo } \\
\text { final (kg) }\end{array}$ & $\begin{array}{l}\text { Peso de carcaça } \\
\text { quente }(\mathrm{kg})\end{array}$ & $\begin{array}{c}\text { Rendimento de } \\
\text { carcaça }(\%)\end{array}$ & $\begin{array}{l}\text { Ganho médio } \\
\text { diário (kg) }\end{array}$ & $\begin{array}{l}\text { Conversão } \\
\text { alimentar }\end{array}$ \\
\hline Silagem de sorgo $+1,0 \%$ concentrado & 323,5 & 543,4 & 293,6 & 53,9 & $1,7 \mathrm{a}$ & $6,9 \mathrm{a}$ \\
\hline Conversão alimentar $+1,2 \%$ concentrado & 335,2 & 504,2 & 276,0 & 54,7 & $1,2 \mathrm{~b}$ & $9,5 b$ \\
\hline
\end{tabular}

Médias seguidas de letras diferentes na coluna diferem entre si $(\mathrm{P}<0,05)$ pelo teste $\mathrm{T}$.

Tabela 4 - Características de carcaça de tourinhos confinados com dietas à base de cana-de-açúcar ou silagem de sorgo

\begin{tabular}{|c|c|c|c|}
\hline & $\begin{array}{l}\text { Silagem de sorgo }+ \\
1,0 \% \text { concentrado }\end{array}$ & $\begin{array}{c}\text { Cana-de-açúcar }+ \\
1,2 \% \text { concentrado }\end{array}$ & $\begin{array}{c}\text { Coeficiente de } \\
\text { variação (\%) }\end{array}$ \\
\hline Conformação & 13,0 & 13,3 & 15,3 \\
\hline Área de olho-de-lombo $\left(\mathrm{cm}^{2}\right)$ & 71,8 & 65,3 & 14,5 \\
\hline Comprimento da carcaça (cm) & $137,9 \mathrm{a}$ & $132,6 b$ & 4,4 \\
\hline Comprimento da perna $(\mathrm{cm})$ & $74,6 a$ & $72,7 \mathrm{~b}$ & 3,7 \\
\hline Espessura do coxão $(\mathrm{cm})$ & 26,3 & 25,8 & 5,4 \\
\hline Marmoreio & 4,5 & 4,0 & 40,0 \\
\hline Osso (\%) & 14,7 & 15,2 & 12,4 \\
\hline Músculo (\%) & 64,3 & 63,7 & 8,2 \\
\hline Gordura (\%) & 21,9 & 21,7 & 17,8 \\
\hline
\end{tabular}

Médias seguidas de letras diferentes na linha diferem entre si $(\mathrm{P}<0,05)$, pelo teste $\mathrm{T}$.

Cor: 1 = escura e 5 = vermelho viva; Textura: 1 = muito grosseira e 5 = muito fina; Marmoreio: $1=$ traço menos e $18=$ abundante mais 
produzir carne com coloração atraente, mesmo com esses animais.

A textura, com média de 4,0 pontos, corresponde a uma textura fina e o marmoreio, com média de 4,3 pontos, corresponde a leve menos. Como animais não-castrados depositam menos gordura intramuscular, os valores encontrados podem ser considerados razoáveis.

O fato de os animais serem jovens e não-castrados explicaria a alta porcentagem de músculo (média de $64 \%$ ) e a baixa porcentagem de gordura (média de 21,8\%) obtida no presente experimento (Tabela 4), uma vez que o tecido ósseo apresenta maior crescimento nas fases iniciais de desenvolvimento do animal, seguido pelo tecido muscular e, por último, pelo adiposo.

\section{Conclusões}

O consumo de matéria seca e a digestibilidade dos nutrientes da dieta não são influenciados pela substituição da silagem de sorgo pela cana-de-açúcar. Entretanto, o desempenho dos animais mantidos com cana-de-açúcar é inferior, mesmo quando fornecido maior percentual de concentrado. Os animais terminados com dietas à base de cana-de-açúcar ou silagem de sorgo apresentam características de carcaça semelhantes, dentro dos padrões de exigências dos frigoríficos e consumidores.

\section{Literatura Citada}

ABRAhÃO, J.J.S.; PRADO, I.N.; PEROTTO, D. et al. Características de carcaças e da carne de tourinhos submetidos a dietas com diferentes níveis de substituição do milho por resíduo úmido da extração da fécula de mandioca. Revista Brasileira de Zootecnia, v.34, n.5, p.1640-1650, 2005.

AROEIRA, L.J.M.; LOPES, F.C.F.; DAYRELL, M.S. et al. Digestibilidade, degradabilidade e taxa de passagem da cana-deaçúcar mais uréia e do farelo de algodão em vacas mestiças Holandês x Zebu em lactação. Revista Brasileira de Zootecnia, v.24, n.6, p.1016-1026, 1995.
COSTA, E.C.; RESTLE, J.; VAZ, F.N. et al. Características da carcaça de novilhos Red Angus superprecoces abatidos com diferentes pesos. Revista Brasileira de Zootecnia, v.31, n.1, p.119-128, 2002.

HANKINS, O.G.; HOWE, P.E. Estimation of the composition of beef carcasses and cuts. Technical Bulletin USDA, n.926, p.1-20, 1946.

MENDONÇA, S.S.; CAMPOS, J.M.S.; VALADARES FILHO, S.C. et al. Consumo, digestibilidade aparente, produção e composição do leite e variáveis ruminais em vacas leiteiras alimentadas com dietas à base de cana-de-açúcar. Revista Brasileira de Zootecnia, v.33, n.2, p.481-492, 2004.

MORAES, K.A.K.; VALADARES FILHO, S.C.; MORAES, E.H.B.K. et al. Cana-de-açúcar tratada com óxido de cálcio fornecida com diferentes níveis de concentrado para novilhas de corte em confinamento. Revista Brasileira de Zootecnia, v.37, n.7, p.1293-1300, 2008a.

MORAES, K.A.K.; VALADARES FILHO, S.C.; MORAES, E.H.B.K. et al. Parâmetros nutricionais de novilhas de corte alimentadas com cana-de-açúcar tratada com óxido de cálcio e diferentes níveis de concentrado. Revista Brasileira de Zootecnia, v.37, n.7, p.1301-1310, 2008b.

MÜLLER, L.; MAXON, W.E.; PALUER, A.Z. et al. Evaluacíon de técnicas para determinar la composición de la canal. In: ASOCIACIÓN LATINOAMERICANA DE PRODUCCIÓN ANIMAL - ALPA, 4. 1973, Guadalajara. Anais... Guadalajara: ALPA, 1973. (sn).

MÜLLER, L. Normas para avaliação de carcaças e concurso de carcaça de novilhos. 1. Santa Maria: Imprensa Universitária - UFSM., 1980. p.31.

NATIONAL RESEARCH COUNCIL - NRC. Nutrient requirements of beef cattle. 7.ed. Washington, D.C.: National Academy Press, 1996. 244p.

PEREIRA, E.S.; QUEIROZ, A.C.; PAULINO, M.F. et al. Determinação das frações protéicas e de carboidratos e taxas de degradação in vitro da cana-de-açúcar, da cama de frango e do farelo de algodão. Revista Brasileira de Zootecnia, v.29, n.6, p.1887-1893, 2000.

SAS INSTITUTE. SAS/STAT. User's guide. Versão 9.1.3. Cary: SAS Institute Inc., 2004. (CD-ROM).

SILVA, D.J.; QUEIROZ, A.C. Análise de alimentos: métodos químicos e biológicos. 3.ed. Viçosa, MG: Universidade Federal de Viçosa, 2002. 235p.

SILVA, J.F.C. Mecanismos reguladores de consumo. In: BERCHIELli, T.T.; PIRES, A.V.; OLIVEIRA, S.G. (Ed.) Nutrição de ruminantes. Jaboticabal: Funep, 2006. p.57-78.

SILVA, J.F.C.; LEÃO, M.I. Fundamentos de nutrição dos ruminantes. Piracicaba: Livroceres, 1979. 380p.

SNIFFEN, C.J.; O'CONNOR, J.D.; VAN SOEST, P.J. et al. A net carbohydrate and protein system for evaluating cattle diets: II. Carbohydrate and protein availability. Journal of Animal Science, v.70, n.11, p.3562-3577, 1992. 